\title{
Electronic Conductivity of NaCl-KCl Equimolar Melt Containing Eu(III) and Eu(II) Complexes by Electrochemical Impedance Spectroscopy
}

\author{
Sergey A. Kuznetsov ${ }^{\mathrm{a}, \mathrm{b}}$ and Marcelle Gaune-Escard ${ }^{\mathrm{b}}$ \\ a Institute of Chemistry, Kola Science Centre RAS, 14 Fersman Str., 184209 Apatity, \\ Murmansk Region, Russia \\ b Ecole Polytechnique, Mecanique Energetique, Technopole de Chateau Gombert, \\ 5 rue Enrico Fermi, 13453 Marseille Cedex 13, France \\ Reprint requests to M. G.-E.; Fax: +33(0)4 911174 39; E-mail: mge@ polytech.univ-mrs.fr
}

Z. Naturforsch. 61a, 486 - 490 (2006); received June 1, 2006

\begin{abstract}
The electronic conductivity of molten equimolar $\mathrm{NaCl}-\mathrm{KCl}$ containing $\mathrm{Eu}(\mathrm{III})$ and $\mathrm{Eu}(\mathrm{II}) \mathrm{com}-$ plexes was studied by electrochemical impedance spectroscopy. The ratio between electronic and electrolyte resistance as a function of the electrode potential was determined. The electronic conductivity was found to be maximal when the amounts of $\mathrm{Eu}(\mathrm{III})$ and $\mathrm{Eu}(\mathrm{II})$ are about equal. The electronic conductivity of this melt does not exceed $2.3 \%$ of the ionic conductivity. Deviation from the molar ratio $\mathrm{Eu}(\mathrm{III}) / \mathrm{Eu}(\mathrm{II})=1$ led to a considerable diminution of the electronic conductivity.
\end{abstract}

Key words: Complexes of Europium; Cyclic Voltammetry; Impedance Spectra; Equivalent Circuit; Electronic and Ionic Conductivity.

\section{Introduction}

Rare-earth metals and their alloys are widely used in modern techniques. Electrowinning and electrorefining are promising methods for the production of highpurity rare-earth metals [1-4]. In order to achieve optimal electrolysis parameters in these processes knowledge of the electronic and ionic partial conductivities is necessary.

It was shown in [5-8] that the conductivity of the redox couples $\mathrm{Nb}(\mathrm{V})-\mathrm{Nb}(\mathrm{IV})$ and $\mathrm{Ta}(\mathrm{V})-\mathrm{Ta}(\mathrm{IV})$ in alkali chloride melts is partly electronic. The electronic conductivity of molten systems can be determined by the Wagner-Hebb method, utilizing a blocked working electrode and a reversible counter electrode, using potentials where the Faraday process does not exist [8]. This method allows to separate electronic and ionic conductivity contributions of the molten electrolyte. The electronic conductivity can also be determined by electrochemical impedance spectroscopy. In many cases, the impedance spectra are characterized by a Warburg transport impedance and are well fitted by an equivalent circuit of the Randles type [9]. The results reported in $[5-8]$ have shown that a perfect fit can be obtained at low frequencies by coupling a resistive element in parallel with the element representing the ionic transfer (Ohmic resistance) of the electrolyte. This parallel resistor may be assigned to an electronic contribution to the electrolyte conductivity [6].

Electronic conductivity in ionic melts containing $\mathrm{EuCl}_{3}$ appears due to $\mathrm{EuCl}_{3}$ decomposition [10 - 12]. Thus in these melts the electronic conductivity would arise from the exchange of the valence electrons between complexes of Eu(III) and Eu(II).

In this article the electronic conductivity in an $\mathrm{NaCl}-$ $\mathrm{KCl}$ equimolar melt containing complexes of $\mathrm{Eu}(\mathrm{III})$ and $\mathrm{Eu}(\mathrm{II})$ was determined by the electrochemical impedance spectroscopy method.

\section{Experimental}

\subsection{Chemicals and Preparation of Salts}

Europium trichloride was synthesized from the oxide $\mathrm{Eu}_{2} \mathrm{O}_{3}$ (Johnsen Matthey, 99.9\%). Thionyl chloride (Jonhson Matthey, 99\%) was used as a chlorinating agent. The $\mathrm{SOCl}_{2}$ vapour was passed through solid $\mathrm{Eu}_{2} \mathrm{O}_{3}$ at $823 \mathrm{~K}$ using argon as a carrier gas during $6 \mathrm{~h}$. Chemical analysis of the prepared $\mathrm{EuCl}_{3}$ was performed by use of mercurimetric (chloride) and complexometric (EDTA in the presence of xylenol orange-europium) methods. The results of the anal- 
Table 1. Chemical analysis of $\mathrm{EuCl}_{3}$.

\begin{tabular}{llll}
\hline & \multicolumn{3}{c}{ mass\% } \\
$\mathrm{Cl}_{\text {experimental }}$ & $\mathrm{Cl}_{\text {theoretical }}$ & $\mathrm{Eu}_{\text {experimental }}$ & $\mathrm{Eu}_{\text {theoretical }}$ \\
\hline 41.18 & 41.17 & 58.82 & 58.83 \\
\hline
\end{tabular}

ysis did show that the molar ratio $\mathrm{Cl} / \mathrm{Eu}$ was essentially three. The chemical analysis of $\mathrm{EuCl}_{3}$ is given in Table 1 . Being highly hygroscopic, $\mathrm{EuCl}_{3}$ was stored in sealed glass ampoules under vacuum. All further handling of europium trichloride was performed in a controlled purified argon atmosphere glove-box (water content less than $2 \mathrm{ppm}$ ). Continuous argon purification was achieved by forced recirculation through external molecular sieves.

$\mathrm{NaCl}$ and $\mathrm{KCl}$ were purchased from Prolabo ( $99.5 \%$ min.). They were dehydrated by continuous and progressive heating just above the melting point under gaseous $\mathrm{HCl}$ atmosphere in quartz ampoules. Excess $\mathrm{HCl}$ was removed from the melt by argon bubbling. The salts were handled in the glove-box and stored in sealed glass ampoules, as explained above.

The total concentration of europium was determined by inductively coupled plasma atomic emission spectroscopy (ICP-AES). Determination of Eu(II) in quenched samples was performed by potentiometric titration with potassium dichromate.

\subsection{Procedures and Electrochemical Cell}

$\mathrm{NaCl}$ and $\mathrm{KCl}$ were mixed in the required ratio, placed in an ampoule made of glassy carbon (GC) of the SU-2000 type and transferred to a hermetically sealed retort of stainless steel. The latter was evacuated to a residual pressure of $0.7 \mathrm{~Pa}$, first at room temperature and then at higher temperatures $(473,673$ and $873 \mathrm{~K}$ ). After this, the retort was filled with highpurity argon and the electrolyte was melted.

Cyclic voltammetry (CV) and electrochemical impedance spectroscopy (EIS) were employed, using a VoltaLab-40 potentiostat operated with the packaged software "VoltaMaster 4", version 6 and the complementary Zahner Im $6 \mathrm{~d}$ unit. The potential scan rate ( $v$ ) was varied between $5 \cdot 10^{-3}$ and $5 \mathrm{~V} \mathrm{~s}^{-1}$. The impedance spectra were recorded from $100 \mathrm{mHz}$ up to $100 \mathrm{kHz}$, and an amplitude of $10 \mathrm{mV}$ was applied. The experiments were carried out at $973 \mathrm{~K}$. The cyclic voltammetric curves and impedance spectra were recorded at a glassy carbon working electrode (1 mm diameter, type SU-2000) with respect to a glassy carbon rod (2 mm diameter, type SU-2000) as a quasi-reference electrode. The glassy carbon plate (surface area $3.6 \mathrm{~cm}^{2}$, type SU-2000) served as the counter electrode. While the potential of this quasireference electrode does not constitute a thermodynamic reference, the use of this electrode was preferred in order to avoid any contact between the melt and oxygen-containing material as used in classical reference electrodes. The potential of the chlorine evolution on the glassy carbon working electrode was used as internal reference potential [13]. During the experiments, the electrochemical cell was kept under an inert argon atmosphere (99.999\%, Air Liquide).

The content of $\mathrm{EuCl}_{3}$ introduced into the $\mathrm{NaCl}-\mathrm{KCl}$ melt was $2 \mathrm{~mol} \%$. A relatively high content was chosen because the electronic conductivity is practically not revealed in diluted solutions containing complexes of mixed valency, due to the shielding influence of cations and anions in the solvent.

\section{Results and Discussion}

A typical cyclic voltammetric curve of an $\mathrm{NaCl}-\mathrm{KCl}$ melt after addition of $\mathrm{EuCl}_{3}$, as obtained at the glassy carbon electrode, is presented in Figure 1. Wave 1 is observed in the cathodic-anodic region and is indicative of the appearance of $\mathrm{Eu}(\mathrm{II})$ in the melt due to the reaction $[10-12]$

$$
2 \mathrm{EuCl}_{3} \rightleftarrows 2 \mathrm{EuCl}_{2}+\mathrm{Cl}_{2} \text {. }
$$

The ratio of $\mathrm{Eu}(\mathrm{III})$ to $\mathrm{Eu}(\mathrm{II})$ at each potential can be calculated from the equation

$$
c_{\mathrm{Eu}(\mathrm{III})} c_{\mathrm{Eu}(\mathrm{II})}=I_{\mathrm{p}}^{\mathrm{c}} \cdot D^{1 / 2}{ }_{\mathrm{Eu}(\mathrm{II})} / I_{\mathrm{p}}^{\mathrm{a}} \cdot D^{1 / 2} \mathrm{Eu(III)},
$$

where $c_{\mathrm{Eu}(\mathrm{III})}$ and $c_{\mathrm{Eu}(\mathrm{II})}$ are the concentrations of $\mathrm{Eu}(\mathrm{III})$ and $\mathrm{Eu}(\mathrm{II})$ complexes in the melt; $D_{\mathrm{Eu}(\mathrm{III})}$ and $D_{\mathrm{Eu}(\mathrm{II})}$ are the diffusion coefficients and $I_{\mathrm{p}}^{\mathrm{c}}$ and $I_{\mathrm{p}}^{\mathrm{a}}$ the cathodic and anodic currents.

The kinetics of the redox electrode reaction

$$
\mathrm{Eu}(\mathrm{III})+\mathrm{e}^{-} \rightleftarrows \mathrm{Eu}(\mathrm{II})
$$

was studied in detail $[10-11]$. It was shown that the process at $v=0.3 \mathrm{~V} \mathrm{~s}^{-1}$ proceeds quasi-reversibly mostly under diffusion control, and the standard rate constant at $973 \mathrm{~K}$ was determined as $8 \cdot 10^{-3} \mathrm{~cm} \mathrm{~s}^{-1}$. The diffusion coefficients of the $\mathrm{Eu}(\mathrm{III})$ and $\mathrm{Eu}(\mathrm{II})$ complexes at the temperature $973 \mathrm{~K}$ were $2.25 \cdot 10^{-5}$ and $4.36 \cdot 10^{-5} \mathrm{~cm}^{2} \mathrm{~s}^{-1}$, respectively.

Figure 2 displays the Nyquist plot and Fig. 3 the Bode plot, obtained at the potential $+0.1 \mathrm{~V}$ vs. the 


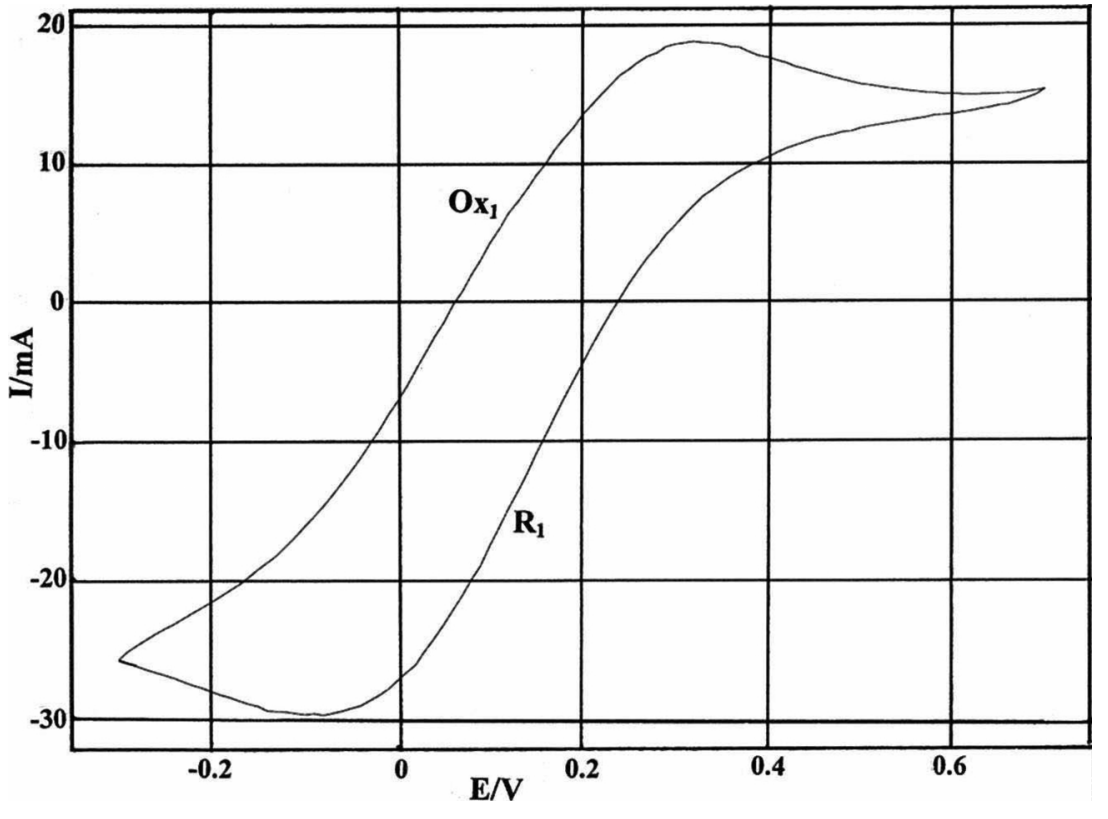

Fig. 1. Cyclic voltammetric curve at the glassy carbon electrode after addition of $2 \mathrm{~mol} \%$ of $\mathrm{EuCl}_{3}$ to an $\mathrm{NaCl}-\mathrm{KCl}$ melt. Area: $0.32 \mathrm{~cm}^{2}$; sweep rate: $0.3 \mathrm{~V} \mathrm{~s}^{-1}$; temperature: $973 \mathrm{~K}$; quasi-reference electrode: glassy carbon.

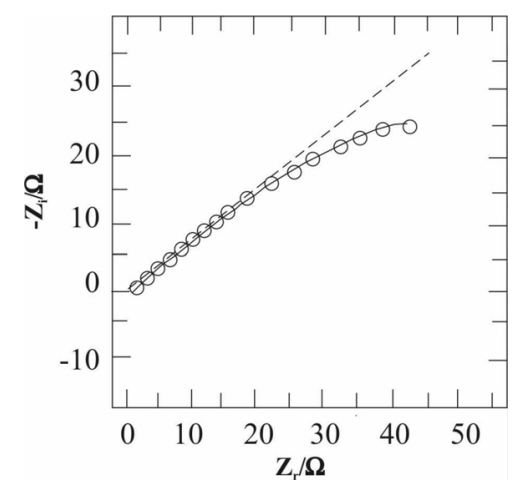

Fig. 2. Nyquist plot of the impedance after addition of $2 \mathrm{~mol} \%$ of $\mathrm{EuCl}_{3}$ to an $\mathrm{NaCl}-\mathrm{KCl}$ melt. Working electrode: glassy carbon; the potential $+0.1 \mathrm{~V}$ vs. the glassy carbon quasi-reference electrode; temperature: $973 \mathrm{~K}$; $\bigcirc$ : modulus of the impedance.

GC quasi-reference electrode. It is well known that the Randles equivalent circuit usually simulates effectively the impedance characteristics of a fast charge transfer reaction at a planar electrode [14]. This circuit includes a parallel combination of the charge transfer resistance in series with the Warburg diffusion impedance and the double layer capacitance. This parallel combination is in series with the electrolyte resistance. A Nyquist plot of the impedance represents a circular arc at high frequencies and a linear behaviour with negative slope -1 at lower frequencies, because the diffusion becomes dominant. The latter is described by the Warburg el-

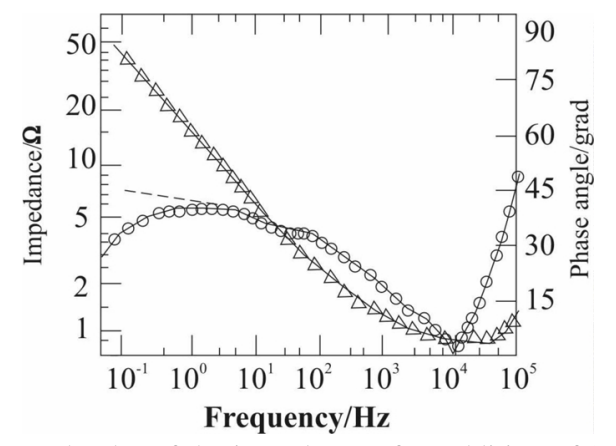

Fig. 3. Bode plot of the impedance after addition of $2 \mathrm{~mol} \%$ of $\mathrm{EuCl}_{3}$ to an $\mathrm{NaCl}-\mathrm{KCl}$ melt. Working electrode: glassy carbon; the potential $+0.1 \mathrm{~V}$ vs. the glassy carbon quasireference electrode; temperature: $973 \mathrm{~K}$; $\triangle$ : modulus of the impedance; $\bigcirc$ : values of the phase angle.

ement. The Warburg impedance is expressed by the equation [9]

$$
\begin{aligned}
& Z_{W}=(1-j) R T(n F)^{-2}(2)^{-1 / 2} w^{1 / 2} \\
& \cdot\left[1 /\left(c_{\mathrm{Eu}(\mathrm{III})} D^{1 / 2} \mathrm{Eu}(\mathrm{III})\right)+1 /\left(c_{\mathrm{Eu}(\mathrm{II})} D^{1 / 2} \mathrm{Eu}(\mathrm{II})\right)\right] .
\end{aligned}
$$

Equation (4) applies strictly to semi-infinite diffusion to a planar surface and if the system is not quiescent, the Warburg impedance takes a different form $[15,16]$ :

$$
\begin{aligned}
& Z_{W}= \\
& R_{\mathrm{CT}}\left[1+\left\{k _ { \mathrm { f } } \mathrm { th } \left(\delta_{\mathrm{N}} j^{1 / 2} w^{1 / 2} D^{-1 / 2} \mathrm{Eu}(\mathrm{III}) /\left(j w D_{\mathrm{Eu}(\mathrm{III})}\right)^{1 / 2}\right.\right.\right. \\
& \left.+\left(k_{\mathrm{b}} \operatorname{th}\left(\delta_{\mathrm{N}} j^{1 / 2} w^{1 / 2} D^{-1 / 2} \mathrm{Eu}(\mathrm{II})\right) /\left(j w D_{\mathrm{Eu}(\mathrm{II})}\right)^{1 / 2}\right\}\right],
\end{aligned}
$$




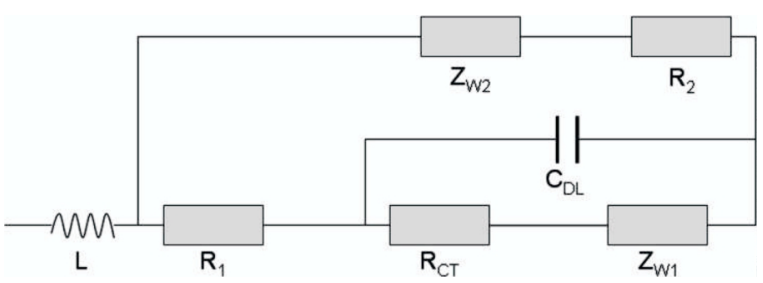

Fig. 4. Equivalent circuit. Description in the text (Results and Discussion).

where $R_{\mathrm{CT}}$ is the charge transfer resistance, th the hyperbolic tangent operator, $\delta_{\mathrm{N}}$ the ideal Nernst diffusion layer thickness, $k_{\mathrm{f}}$ and $k_{\mathrm{b}}$ are the rate constants in the forward and reverse direction.

Analysis shows that at $w \rightarrow 0, \quad Z_{W} \rightarrow$ $R_{\mathrm{CT}}\left(k_{\mathrm{f}} \delta_{\mathrm{N}} / D_{\mathrm{Eu}(\mathrm{III})}\right)$, and if the diffusion layer has a finite thickness, the impedance at low frequencies lies below the Warburg impedance [16]. Probably this is the reason for the deviation from the slope -1 in our case (Fig. 2). Nevertheless, utilization of the Nernst diffusion element did not provide a good fit of our experimental data.

After the abovementioned analysis for the simulation of the impedance characteristics, an equivalent circuit similar to that reported in [6] was used (Fig. 4). In this circuit: $\mathrm{L}$ is the inductivity in cables, $\mathrm{R}_{1}$ represents the Ohmic resistance of the electrolyte, $\mathrm{R}_{\mathrm{CT}}$ the charge transfer resistance, the Warburg impedance $\mathrm{Z}_{\mathrm{W} 1}$ represents the diffusion of ionic species, $\mathrm{C}_{\mathrm{DL}}$ the capacitance of the double layer, $\mathrm{R}_{2}$ the electronic resistance and $\mathrm{Z}_{\mathrm{W} 2}$ a Warburg-like element which constitutes diffusion of electrons.

The connection of elements $\mathrm{R}_{2}$ and $\mathrm{Z}_{\mathrm{W} 2}$ parallel to the ionic elements $\mathrm{R}_{1}, \mathrm{R}_{\mathrm{CT}}, \mathrm{Z}_{\mathrm{W} 1}$ and $\mathrm{C}_{\mathrm{DL}}$ indicates that the charge transfer through the electrochemical cell occurs due to an ionic process or to electronic conductivity. The full lines in Fig. 2 and 3 correspond to the equivalent circuit (Fig. 4), and the dashed lines show fits without taking into consideration the electronic conductivity (element $\mathrm{R}_{2}$ of the circuit).

As can be seen from Fig. 2 and Fig. 3, the experimental data and simulated curves agree well. It was found that the resistance due to diffusion of electrons is negligible, because the equivalent circuit $\mathrm{Z}_{\mathrm{W} 2}$ has values in the pico capacity range.

In particular, significant for our study are the values of $R_{2}$ and $R_{1}$ in the equivalent circuit, which correspond to electronic and electrolyte resistance. At the potential $+0.1 \mathrm{~V}$ relative to the GC quasi-reference

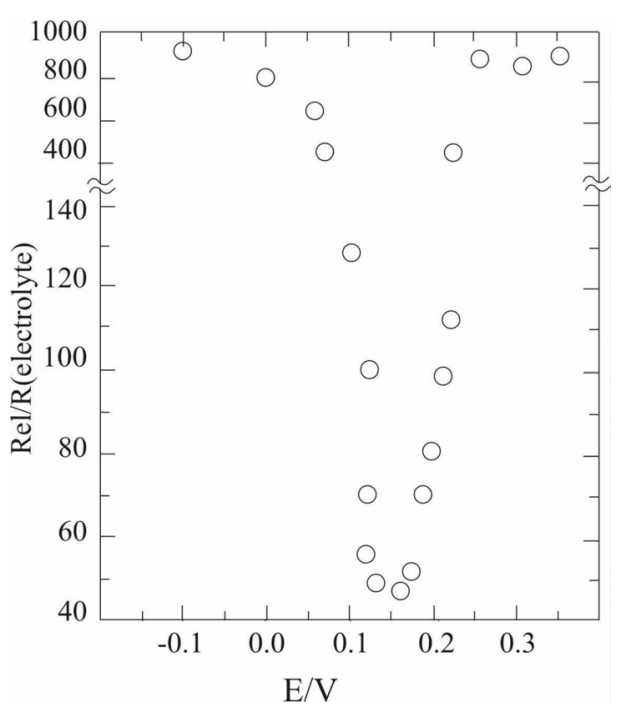

Fig. 5. Ratios between electronic resistance and electrolyte resistance as a function of electrode potentials for an initial content of $2 \mathrm{~mol} \% \mathrm{EuCl}_{3}$ in $\mathrm{NaCl}-\mathrm{KCl}$ melt. Working electrode: glassy carbon; quasi-reference electrode: glassy carbon; temperature: $973 \mathrm{~K}$.

electrode, the values $0.967 \Omega$ and $124 \Omega$ were determined for the electronic and electrolyte resistance, respectively. Thus at this potential the fraction of electronic conductivity is less than $1 \%$ of the ionic conductivity. However, this value cannot be neglected because including electronic conductivity to the equivalent circuit significantly improves the fitting of the experimental data (Figs 2,3) and suggests that the model agrees with the electrical analogues.

The ratio between electronic resistances and electrolyte resistances as a function of electrode potentials is shown in Figure 5. It is necessary to note that after each impedance measurement the rest potential of the GC quasi-reference electrode was controlled. The most appropriate method for doing so is the determination of the chlorine evolution potential. The reason of the shift rest potential is the change of the molten salt composition, because the $\mathrm{Eu}(\mathrm{II}) / \mathrm{Eu}(\mathrm{III})$ molar ratio may increase during the experiment because of reaction (1). Another melt with the same initial composition was used for measurements if the shift of the rest potential exceeds $20 \mathrm{mV}$.

As can be seen from Figs. 1 and 5, a relatively sharp maximum of the electronic conductivity was observed for the melts with the $\mathrm{Eu}$ (III) to $\mathrm{Eu}$ (II) molar ratio close to unity. The values of electronic conductivity for these melts were around $2.0-2.3 \%$ of the ionic conductivity. The deviation of the $\mathrm{Eu}(\mathrm{III}) / \mathrm{Eu}(\mathrm{II})$ molar ratio from 
unity led to a significant diminution of the electronic conductivity.

Acknowledgements

S. A. K. wishes to thank the Ecole Polytechnique de Marseille for hospitality and support of this study.

[1] S. Singhand and J. Balachandra, J. Electrochem. Soc. India 22, 226 (1973).

[2] V. A. Lebedev, Selectivity of Liquid Metal Electrodes in Molten Halides, Metallurgiya, Chelyabinsk 1993.

[3] L. Feng, C. Guo, and D. Tang, J. Alloys Compd. 234, 183 (1996).

[4] Y. Yamamura, I. Wu, H. Zhu, M. Endo, N. Akao, M. Mohamedi, and Y. Sato, Molten Salt Chem. Technol. 5, 355 (1998).

[5] M. Bachtler, W. Freyland, G. A. Voyiatzis, and G. N. Papatheodorou, Ber. Bunsenges. Phys. Chem. 99, 21 (1999).

[6] U. Stohr, P. R. Bandi, F. Matthiesen, and W. Freyland, Electrochim. Acta 43, 569 (1999).

[7] U. Stohr and W. Freyland, Electrochim. Acta 44, 2199 (1999).

[8] U. Stohr and W. Freyland, Phys. Chem. Chem. Phys. 1, 4383 (1999).

[9] J. R. Macdonald, Impedance Spectroscopy, John Wiley and Sons Inc., New York 1987.
[10] S. A. Kuznetsov, L. Rycerz, and M. Gaune-Escard, Z. Naturforsch. 56a, 741 (2001).

[11] S. A. Kuznetsov and M. Gaune-Escard, Electrochim. Acta 46, 1101 (2001).

[12] L. Rycerz and M. Gaune-Escard, Z. Naturforsch. 57a, 215 (2001).

[13] S. A. Kuznetsov, Electrochemical Techniques, in: Molten Salts: From Fundamentals to Applications. Proceedings of the NATO Advanced Study Institute (Kas, Turkey, May 4-14, 2001), NATO Science Series II, Vol. 52 (Ed. M. Gaune-Escard), Kluwer Academic Publishers, Dordrecht 2002, p. 375.

[14] D. D. Macdonald, Transient Techniques in Electrochemistry, Plenum Press, New York 1977.

[15] C. Gabrielli, Identification of Electrochemical Processes by Frequency Response Analysis, Technical Report No 004/83, SOLATRON Instruments, Farmborough 1984.

[16] D. D. Macdonald, Electrochim. Acta 51, 1376 (2006). 